\title{
Ponto DE VISTA
}

\author{
Big Brother Brasil, A Gladiatura Pós-Moderna
}

\author{
Marion Minerbo ${ }^{1}$ \\ Sociedade Brasileira de Psicanálise de São Paulo - SBPSP
}

\begin{abstract}
Uita gente fica intrigada com o sucesso do chamado reality show Big Brother Brasil (BBB). Os comentários, ao menos por parte de certo segmento sociocultural, são de que o programa é a própria celebração da mediocridade. As pessoas "caem matando" - a expressão é importante - tanto no programa, quanto no nível dos participantes. Mas, se faz sucesso, é porque responde a alguma demanda dos telespectadores. De algum modo, o sucesso sempre tem sentido. Mas qual? Desconfio de interpretações fáceis como "a platéia também é medíocre" ou "somos todos voyeurs". Neste pequeno artigo, tentei ir além do senso comum, ensaiando uma interpretação psicanalítica desse fenômeno contemporâneo.
\end{abstract}

O BBB dispensa maiores apresentações: mesmo quem nunca assistiu, tem uma idéia do que se trata. O programa se estrutura em torno de um suspense e da participação do público, que vota semanalmente em quem será excluído, ou melhor, em quem irá para o "paredão". Para que o público possa votar, a atuação dos participantes no dia-a-dia do programa é decisiva. Aparentemente, estão apenas conversando, namorando, fazendo ginástica, indo a festas. Mas nós (e eles) sabemos que estão se digladiando para eliminar os

1 Membro efetivo da Sociedade Brasileira de Psicanálise de São Paulo, Doutora em Medicina pela UNIFESP. Endereço eletrônico: marion.minerbo@terra.com.br

Psicologia USP, 2007, 18(1), 153-158. 


\section{Marion Minerbo}

outros e vencer. Fazem alianças, traem, simulam, dissimulam, enfim, tentam agradar os eleitores. É tudo ou nada: ou a celebridade instantânea, ou a volta ao anonimato que, na sociedade do espetáculo, é, simbolicamente, o mesmo que morrer. É, pois, uma luta de vida ou morte. Vence o melhor, segundo critérios não muito claros. Simpatia? Amizade? Sedução? Esforço pessoal? A fraqueza ou a desvantagem de um dos competidores? Pode ser que não haja critério algum operando em nível consciente, mas simplesmente o "jeito" da pessoa, que agrada ou não à maioria.

O fato é que "paredão", para nós, brasileiros, é uma clara referência à morte. Disse acima que "as pessoas caem matando" sobre o programa e o nível dos participantes. E, quando escrevi que eles se digladiam pela sobrevivência, fiz nova referência à morte, dessa vez, evocando a gladiatura romana. $\mathrm{O}$ psicanalista trabalha com a linguagem, em seu sentido mais amplo. Toma o discurso do paciente (ou o texto, ou o fenômeno social) ao pé da letra, valoriza cada palavra dita, e também a que não foi dita. Segue o fio da meada das palavras, para ver onde vai dar. Vejamos.

Como os participantes do BBB, os gladiadores também lutavam entre si até o fim. Quando o gladiador vitorioso encurralava o oponente, convocava o voto popular, que podia ser referendado pelo imperador: polegar para cima, vida; polegar para baixo, morte. A vida do perdedor podia ser poupada, se o público o considerasse um lutador valoroso e digno. Em caso contrário, "paredão".

A luta entre os gladiadores, ou entre feras e gladiadores, era totalmente realista, e isso empolgava as platéias de Roma. Tratava-se, de certa forma, de um reality show. Era parte da estratégia de despolitização do povo - a conhecida política do pão e circo. Os participantes eram escolhidos em função de seu porte, de sua força e de seu físico. Eram treinados para proporcionar um bom espetáculo, combatendo com bravura e morrendo com dignidade. Podiam ser escravos, prisioneiros de guerra ou cristãos, mas até mesmo homens livres se candidatavam, pois era um caminho possível e rápido para a ascensão social. A entrada no Coliseu era gratuita, e as pessoas da platéia podiam apostar no seu favorito. A gladiatura era tema das conversas no dia-a-dia. O leitor pode encontrar facilmente os pontos de aproximação com o BBB.

O programa escolhe os jovens participantes de modo a oferecer suportes identificatórios para os vários perfis de telespectadores. Além disso, como 
o voto para a exclusão sistemática envolve toda a população, esta se identifica também com o lugar do poderoso, que ergue ou abaixa o polegar. E, evidentemente, com o sobrevivente, pois, durante o processo, fazemos a catarse da angústia que nos assombra no cotidiano: a angústia da exclusão social, digital, do mercado de trabalho etc. Até a semana que vem, se tudo correr bem, continuamos no páreo.

Há outro elemento que entra na análise do BBB e que, a meu ver, é o decisivo para caracterizá-lo como espetáculo pós-moderno e para compreender seu sucesso. Como na gladiatura, o reality show oferece carne humana para nosso repasto. Somos também o leão na arena, como veremos.

Em outro artigo (Minerbo, no prelo), faço uma análise do filme $L a$ ranja Mecânica, de Stanley Kubrick (1971). Ali, mostro que a distância entre a coisa e o símbolo vem diminuindo progressivamente, a ponto de o símbolo já não se sustentar na ausência da coisa, precisando da presença "de verdade" do simbolizado. No filme, a gangue de Alex brinca de atacar pessoas que simbolizam uma civilização em seu ocaso, mas os ataques são de verdade, donde o nome reality game. $\mathrm{O} 11$ de setembro, por exemplo, foi um ataque a um símbolo do capitalismo, as Torres Gêmeas, mas foi um ataque "de verdade", pois as torres realmente ruíram, matando milhares de pessoas. Em vários fenômenos contemporâneos (body art, certos crimes em que pais matam filhos e vice-versa), observamos uma mesma lógica subjacente: a fratura do símbolo e a desnaturação da linguagem.

No reality show, faz-se do defeito, virtude. A graça toda consiste em não sabermos ao certo quanto de representação e quanto de realidade há naquilo tudo. O reality show é um espetáculo e, ao mesmo tempo, é "de verdade". Os participantes do BBB são pessoas comuns lutando por ascensão social e, nesse sentido, são "de verdade”. Mas há uma dimensão de representação, já que se trata de um jogo em que eles representam pessoas comuns lutando por ascensão social.

Mas quanto realismo é admitido? Nesse BBB7, não há mais os participantes sorteados, que eram "de verdade demais" - feios, gordos, velhos, pobres, ignorantes, sem sex appeal - e que, pasmem, acabaram vencendo o último BBB! Provavelmente estragava o suspense, pois o critério para a votação tornou-se muito evidente: favorecer o desfavorecido. 


\section{Marion Minerbo}

Mas também não pode haver realismo de menos. $\mathrm{O}$ organizador do programa tem que aparecer o mínimo possível, ocultando seu caráter de espetáculo. O BBB nos é apresentado como realidade, e assim deve parecer, embora haja, obviamente, alguém que edita, ainda que minimamente, as filmagens. O sucesso do BBB depende de um equilíbrio perfeito entre realismo demais e realismo de menos.

Pois bem, sem desconhecer o lado de representação do reality show - sabemos que é um show - vou enfatizar o reality, isto é, sua dimensão realista, "de verdade", pois é essa que nos coloca na posição de leões, isto é, de devoradores de carne humana. Quando assistimos a um espetáculo nos moldes clássicos - teatro, circo, e mesmo a novela, já que estamos falando de televisão -, há, entre nós e o corpo dos atores, mediações simbólicas importantes. Seu corpo é o suporte do roteiro, de personagens laboriosamente construídos, há o talento, a iluminação, o palco, enfim, uma série de recursos que se interpõem entre nós e eles. Graças a essas mediações, o corpo do ator transcende seu estatuto de mera exibição de carne humana e passa a ter valor simbólico, tornando-se ator no sentido forte da palavra. Ele passa a ser o suporte necessário para a expressão do talento (ou mesmo para a falta dele - aqui, o que vale é a intenção). No espetáculo clássico, o corpo é representação. No BBB, o corpo é obsceno, não porque esteja quase nu, mas porque é um corpo-carne, sem valor simbólico, pura realidade, excessivamente "de verdade" quando comparado com o corpo do teatro, do circo ou da novela. Obsceno: fora da cena - da cena simbólica.

No circo, há uma condição em que essa distância entre o corpo-carne e o corpo-representação diminui até quase desaparecer: é quando se apresentam o anão e a mulher barbada. Ainda assim, eles têm um lugar simbólico legítimo na estrutura circense: eles estão no picadeiro. Tampouco no strip-tease estamos diante de um corpo-carne, pois há o talento da dançarina em desnudar-se. Eles não se exibem como se estivessem em suas casas, exibem-se para nós. Nenhum desses casos é um reality show.

No reality show, o corpo apresentado é o real. Os jovens estão naquela casa preparando um suco de laranja, nadando na piscina, namorando, dormindo e se digladiando por um lugar ao sol no futuro, e tudo isso é "de verdade". A casa em que eles vivem nos meses de duração do show não tem o mesmo estatuto simbólico de um palco, de um picadeiro ou de uma arena, como na 
gladiatura. Eles não vão para suas casas para dormir, voltando no dia seguinte. É realmente uma casa, com quartos, cozinha, banheiro, piscina. É claro que é uma casa especialmente preparada para esse fim - é uma casa literalmente cinematográfica: há câmeras em todos os aposentos. Nos bastidores, sabemos, está o apresentador, e precisamos ignorar isso para entrar no espírito da coisa.

Mas os diálogos certamente não provêm de um roteiro; os jovens não estão representando personagens. Os participantes são apenas o que são: participantes. Contudo, diferentemente de um jogo, em que há as regras do jogo, ou da novela, em que há um roteiro, na casa do BBB eles farão mais ou menos o que fariam na vida real; dirão mais ou menos o que diriam na vida real. E, sem roteiro, ninguém foge ao que é - ninguém pode ser muito diferente do que determina seu inconsciente.

Lançados num palco, sem roteiro, bons atores improvisam bem, maus atores improvisam mal. Mas no reality show as pessoas são obrigadas a ser o que são "de verdade". Nesse sentido, estão realmente expostas, e em três sentidos: ao nosso massacre - "como são medíocres!" -, ao paredão e, principalmente, expostos em toda sua nudez psíquica. E aqui começa a violência do espetáculo - violência que a plebe consome com prazer. Sem o saber, os participantes estão expostos ao público como carne humana. Assim como o gladiador enfrenta o leão praticamente desarmado, apenas com um escudo, eles se expõem e enfrentam o público desarmados, diretamente, sem a proteção das mediações simbólicas - ou com mediações simbólicas mínimas, quando se lembram de que "é apenas um jogo". Aliás, há os que fazem questão de ter isso sempre em mente - proteção necessária - e os que detestam se lembrar disso. De qualquer forma, entre nós e eles não há nada. Se eles são ridículos, ou medíocres, não é porque o personagem que representam seja ridículo ou medíocre, mas porque eles o são. Tanto quanto na gladiatura, há violência nessa relação não mediada com o corpo do outro. Há violência no consumo do corpo-carne do outro. ${ }^{2}$

O público desses shows aprecia não propriamente o ridículo da participação de um ou a simpatia do outro, mas a obscenidade e a violência que

2 Em exposição realizada na OCA, na cidade de São Paulo, "Corpo humano, real e fascinante", cadáveres de verdade artisticamente preparados fazem o sucesso da mostra precisamente graças a essa dupla condição. 


\section{Marion Minerbo}

marcam a ausência de mediações simbólicas na relação com o outro. É a gladiatura pós-moderna. Nesse sentido, o espetáculo é feito sob medida para a nossa época e merece o sucesso que tem.

\section{Referências}

Kubrick, S. (Diretor). (1971). Laranja mecânica [filme]. Inglaterra: Warner.

Minerbo, M. (no prelo). Reality game: violência contemporânea e desnaturação da linguagem. Ide.

Recebido em:26/02/2007

Aceito em: 9/03/2007 